\title{
Investigating the Mutual Adaptation Process in Teachers' Design of Technology-Infused Curricula
}

\author{
Brian J. Reiser, James P. Spillane, Franci Steinmuller, \\ Don Sorsa, Karen Carney, \& Eleni Kyza, \\ Northwestern University, 2115 N Campus Dr, Evanston IL 60208 \\ Tel: 847-467-2205 Fax: 847-491-8999 \\ Email: reiser@nwu.edu, j-spillane@nwu.edu,f-steinmuller@nwu.edu, \\ d-sorsa@nwu.edu, k-carney@nwu.edu, kyza@ils.nwu.edu
}

\begin{abstract}
We investigate the challenges that face teachers in their role as collaborators in the design of technology infused reform, and the challenges they perceive in making inquiry and technological tools an integral part of their teaching practice. Teachers' concerns about students, both technology-related and concerns about the difficulty of the academic tasks, outweighed those about teaching. Teachers' task concerns had to do chiefly with the ambitious and open-ended nature of the task and whether students would have the necessary background conceptual knowledge and skills. We also examine the solutions teachers developed to address these concerns, and illuminate important differences between the stance of researchers and that of teachers in the collaborative design process.
\end{abstract}

Keywords: science education, curriculum, teacher beliefs and practices, technology planning

\section{Introduction}

The goal of integrating learning technologies into K-12 teaching faces substantial implementation obstacles. In addition to the need for learning the skills to work effectively with new computer technologies, the promise of educational technology frequently relies on changes in teachers' core pedagogical practices (PCAST, 1997). Capitalizing on the promise of giving students powerful tools requires adopting constructivist teaching approaches that represent real changes in practice for many teachers. How do teachers perceive the promise and the challenges of technology for their classrooms? What are the ways they can overcome these obstacles and develop strategies that incorporate technology into more ambitious teaching and learning settings?

Promising ideas about teaching and learning face substantial challenges in moving into practice. Local implementation of reform necessarily involves adaptation rather than "pure" implementation. Interventions are successful when the implementation involves mutual adaptation, in which external reform proposals are adapted to fit local conditions and local conditions are adapted to fit with reform proposals (McLaughlin, 1987). However mutual adaptation tends to be the exception rather than the norm in educational reform, especially reforms that seek substantial transformations of extant practice (Firestone, 1989; Fullan, 1991). Rather, local adaptation is typically a one-sided affair in which reforms are adapted to fit local practice, with minimal changes to local practice. Local adaptation often results in deleterious adaptations that can change reformers' core intent (Spillane, 1999).

One way to plan for mutual adaptation is to involve practitioners in the design of the implementation of the reform, and to create a context that is supportive of planful and reflective adaptation. The goal is to engender better understanding and stronger commitment to the spirit of the reforms.

\section{"Work Circles" of Urban Teachers and Researchers}

In this paper, we explore an attempt to involve teachers in the collaborative design of curriculum incorporating learning technologies. The context was a curriculum design team for middle years science created by the Center for Learning Technologies in Urban Schools (LeTUS). The process of mutual adaptation is a cornerstone of the LeTUS reform efforts - by involving teachers and administrators in working to design solutions, practitioners recreate reform ideas in ways that work for them. The challenge given LeTUS teams, called "work circles," was to design curricula for middle school Chicago classrooms that incorporated interactive learning environment brought to the team by researchers. The stated goals for the curricula were three-fold: The curricula should be project-based to engage students in sustained meaningful investigations (Blumenfeld, Soloway, Marx, Krajcik, Guzdial, \& Palincsar, 
1991); technological tools should be an integral part of the investigations; and the curricula should satisfy the national and local science standards.

We examine one of these work circle teams as a case study of the mutual adaptation model. We examine the process of design and adaptation that occurred. Our aim is to characterize the challenges that face teachers in their role as collaborators in the design of reform, and the challenges they perceive in making inquiry and technological tools an integral part of their teaching practice. To this end, we address four questions. First, what issues did teachers identify in planning how to incorporate learning technologies in their classrooms? Understanding these concerns is key, because some teachers never get beyond these initial objections in considering whether to adopt a new curriculum or teaching approach. Second, we consider the strategies that the team used to address these concerns. These strategies illuminate teachers' models of effective pedagogy, and if successful, can reveal how reforms can be adapted to a local context. Third, we examine the process of the design team itself, to understand how teachers and researchers interacted to construct solutions. Finally, we consider whether the design team was an effective vehicle for mutual adaptation - that is, did the process of creating implementation strategies provoke shifts in teachers' thinking and practice.

\section{The Ecology and Evolution Work Circle}

We examine a work circle established to design a middle years science unit teaching ecology and evolution. LeTUS faculty held initial meetings with Chicago principals to explore their school's participation. Interested principals then recruited teachers from their schools to participate. The Ecology and Evolution team began with an initial meeting in which the researchers demonstrated and discussed three software investigation environments that had been piloted in area high schools. The team then selected The Galapagos Finches around which to base their unit. The Galapagos Finches allows students to study the principles of ecological systems and natural selection in the context of a case of an island ecosystem under crisis (Tabak, Smith, Sandoval, \& Reiser, 1996). The environment is designed to help students learn investigation strategies by making strategies for reasoning about and arguing from data more explicit.

The original team was composed of five teachers from two Chicago public schools, a Northwestern University faculty member who led the team, and two Northwestern graduate students. Two math/science teachers participated from International, a K-8 bilingual magnet school, and two science teachers and one language arts teacher joined from Elmvale Middle School. Both schools serve diverse populations that are typical of Chicago schools: International's student population is approximately 60\% low income, 69\% Hispanic, and 15\% African American with reading and math test scores in the 50-60th percentile. Elmvale has 90\% low income students, $85 \%$ Hispanic, and 8\% African American with test scores in the 30-40th percentile. About 1/3 of the students at each school are categorized as limited English proficient.

The team met approximately bi-weekly for five months, beginning in January 1998. Within the first few weeks two teachers (the language arts teacher from Elmvale and one science teacher from International) dropped out of the group, stating that they were unable to commit the time required. Another science teacher from International then joined, resulting in a continuing group of four science teachers, two from each school.

The meetings started with general topics, such as which software to use and a target grade level. Subsequent meetings focused on deciding the science learning objectives from state and city science standards, and then shifted to discussing possible activity designs. Typically individual teachers wrote drafts which the group later reviewed. The designed activities included readings and discussion, library research, graphing activities, softwarebased activities, journaling, and presentations. In the fourth month, teachers began to pilot activities, and the meetings shifted from discussing hypothetical designs to evaluating and redesigning them, and focusing on creating a written curriculum to be shared with other teachers. Two teachers, one from each school, chose to pilot the unit in their classrooms. These same two teachers then presented the unit in a one-week LeTUS workshop attended by other Chicago teachers in July 1998. In the following year, these two teachers worked with the researchers to elaborate the written drafts (e.g., clarifying procedures, inserting "teacher notes") for distribution of a printed curriculum to new teachers. Our study of the work circle focuses on the first design phase, from January through July 1998, examining the group from its initial design and pilot until the presentation to other teachers at the first summer workshop. 


\section{Unpacking the Local Adaptation Process}

Our goals in the analyses are to understand the adaptation from the perspective of the teachers. What issues did they raise for the team to address? What were the implications of their views of teaching and learning for the creation of a project-based science unit? How did they see the technology fitting into their teaching? What changes did they need to consider before being comfortable with the technology? In this analysis, we examine the various stages of collaborative design and adaptation: (a) identification of problems, (b) proposing solutions, and (c) evaluating and making decisions about solutions.

\section{Methods}

To examine the adaptation process, we reviewed the field notes from work circle meetings. These field notes contained a close tracking of the conversation, capturing each turn of the conversation and a paraphrase of each speaker's comment. Additional sources of data about teachers' views included copies of materials handed out at the meetings (summaries of previous meetings, drafts of activities submitted by team members), a structured interview about pedagogical goals and practices, observations of two teachers' science classrooms during the pilot, and a focus group and interviews with the work circle teachers following the pilot of the unit. Our analyses in this paper focus primarily on the work circle field notes and meeting documents. We present additional data from the interviews to help contextualize our interpretations.

We conducted two types of analyses of the work circle process. First, we read through the records and documents of work circle meetings and attempted to identify key themes that characterized the conversations. What kinds of topics arose? What kinds of goals and interactions took place between the team members? How did decision making proceed?

We conducted a second analysis at the level of conversational turns, to produce a more fine-grained coding of the ideas discussed by the teachers. We developed codes for two types of statements in the work circle meetings, concerns and strategies. Concerns were statements in which a teacher expressed an issue that they felt deserved attention by the group. The concern might be an expression of doubt or hesitation, or might be a constructive suggestion about an issue that the group needed to address in the unit design. Strategies were proposals for ways to deal with identified issues. We coded each time a teacher expressed a concern or strategy, rather than the individual sentence or utterance.

We developed the codes inductively by analyzing a sample of the field notes and clustering similar concerns into categories. Two raters were trained on this coding scheme and applied it to the full set of meeting notes. They identified instances of ambiguities or statements missed by the coding scheme, and the scheme was revised and extended to deal with these cases. The two coders then independently coded eight meetings from February through April that took place prior to the piloting of the unit. Their agreement was approximately $85 \%$.

\section{Teachers' Concerns}

We first examine the identification of problems. Teachers' concerns fell into three main categories (Table 1). First, some concerns were raised about difficulties students might have with the technology. For example, teachers were concerned about whether their students could navigate the software and whether the software was simply too complex. Second, teachers expressed concerns about whether their students would be successful in the academic tasks. For example, teachers expressed some doubts about whether students would understand the task and whether they had the skills to plan and manage the investigation. Finally, a third type of issue stated a difficulty the unit would pose for teachers, such as time demands or difficulty managing the classroom.

We first consider the relative occurrence of each of these types of concerns. Understanding which concerns were driving the discussions and design work reveals the obstacles teachers see in incorporating these types of innovations in their teaching. Our first analysis focuses on the relative frequency of concerns across the set of meetings about students and technology, students and task, and teaching considerations (see Figure 1). 
Table 1: Examples of Issues Raised by Teachers

\begin{tabular}{|c|c|}
\hline Concern Type & Example \\
\hline \multicolumn{2}{|l|}{ Students and Technology } \\
\hline Software Complexity & $\begin{array}{l}\text { José: The software is complicated, navigation is hard for kids. It would take } \\
\text { training. There are too many screens to stay clear about what's going on. }\end{array}$ \\
\hline $\begin{array}{l}\text { Information Management in the } \\
\text { Software }\end{array}$ & $\begin{array}{l}\text { Ellen: It's overwhelming. I would like the kids to take their own notes. I } \\
\text { think for my kids they would get lost with all that information. }\end{array}$ \\
\hline \multicolumn{2}{|l|}{ Students and Academic Task } \\
\hline Prerequisite Skills & Ellen: My kids don't have a clue how to graph... \\
\hline Understanding the Task & $\begin{array}{l}\text { Deb: I am afraid they'll get an answer by trial and error and it won't be the } \\
\text { right one, but they'll decide they're done. }\end{array}$ \\
\hline Managing Investigation & José: This is overwhelming data, they can get lost. \\
\hline \multicolumn{2}{|l|}{ Teaching Considerations } \\
\hline Resources & $\begin{array}{l}\text { Ellen: How many computers there will be in the room because this might } \\
\text { affect what kind of pre-activities we need in order to keep the kids busy. }\end{array}$ \\
\hline Time & $\begin{array}{l}\text { Deb: Other curricula give you pages and pages of stuff for teachers to read } \\
\text { and we don't have time. }\end{array}$ \\
\hline
\end{tabular}

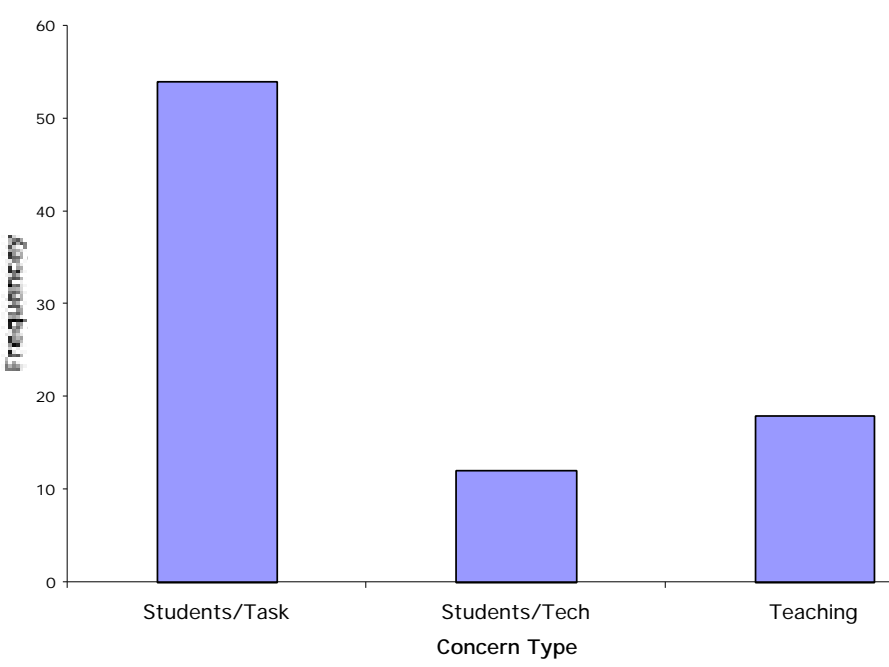

Figure 1. Total concerns about students and teachers expressed by teachers at the work circle meetings.

The first pattern to note is that the concerns about students outweigh those about teaching considerations. This is an intriguing result. Technology and project-based science present new challenges for both students and teachers. If teachers perceive these learning activities as a new type of teaching situation, it seems reasonable that they would focus on the challenges they expect to encounter in orchestrating these activities. However, the work circle teachers most often articulated these concerns in terms of the challenges posed for students. They articulated potential problems in terms of difficulties their students might encounter in understanding how to do the task, navigating the software, and so on, rather than articulating the teaching challenges in helping students understand how to do inquiry.

One possible explanation for this is that teachers' ideas about inquiry projects do not always concur with the features researchers envision as key (Walker \& Gomez, 1998). So while teachers may have seen the type of inquiry described by the researchers as more extensive investigations than they have provided for their students, they did not perceive that this inquiry is different in kind, and they felt capable in teaching this type of project-based approach. For example, José was asked whether the unit his team designed differed from other types of teaching he had done that year: "Obviously the main difference is the computer usage, but the ideas and the goals are similar to many others that I'm sure our teachers have in mind, but don't necessarily function as well as this one does, because it worked tremendously... A lot of the time, with ideas like this that come into our minds, we don't necessarily have 
the time or the support from others to make it feasible to run." His comments point to the complexity of what was achieved by the students, but places the pedagogy within his and his peers' goals and capabilities.

A second interesting pattern is that concerns about the students' encounters with the task far outweighed issues raised specifically about the technology. One might have expected that the technology itself would be the focus of most of the concerns identified by the teachers. The teachers joined the work circles to learn how to integrate technology into their classrooms. The use of the computers themselves represented the most obvious change they were considering in their practice. They did not come to learn about new teaching approaches. Yet it was not a concern with students using the technology per se that occupied these teachers. While there were some concerns about the complexity of the interface or the data in the software, they focused more often on the complexity and challenge of the learning activities the technology made possible.

Consider the following example. This conversation occurred in late February during the third meeting of the team. The meeting began with the group reviewing the software. The conversation ensued following some initial comments about specific aspects of the software they found complex.

\begin{tabular}{|cl|}
\hline Students/Task & Joan: There's a lot here. You could spend more than a week if you don't focus. \\
& Faculty Researcher: We need to decide what to do about this. \\
& José: With ninth graders, how did teachers structure expectations for data? \\
& Faculty Researcher: They gave general guidelines. They needed two kinds of data, \\
& field notes and graphs, to support their claims. We could build in expectations. \\
Students/Task & José: I can see some kids generating data and deciding they are done. \\
Solution: Structure & José: We might want a rubric for support. \\
\hline
\end{tabular}

This is a typical comment in which the teacher raises an issue that he or she feels the group needs to consider in their design. While some comments were about specific things that were complex in the software, such as the potential to have too many open screens, the complexity of specifying queries to find the right data, or the ability to navigate through saved work, much of the discussion moved quickly to the learning activities that this type of complex tool made possible. In this case, teachers worried about asking students to construct arguments from converging evidence, and wondered whether students would be able to evaluate when they had enough data for a good explanation ("deciding they are done" too early). Consider also the relative focus on students and teachers in this dialogue. Clearly this example raises an issue about the complexity of the instructional interaction, which poses challenges both for students and for teachers. However, in these conversations, teachers typically focus on what the challenges will be for their students.

We turn next to the teachers' views of the specific difficulties they expected their students to face concerning the academic tasks. Figure 2 presents a breakdown of the comments in the Students/Task category.

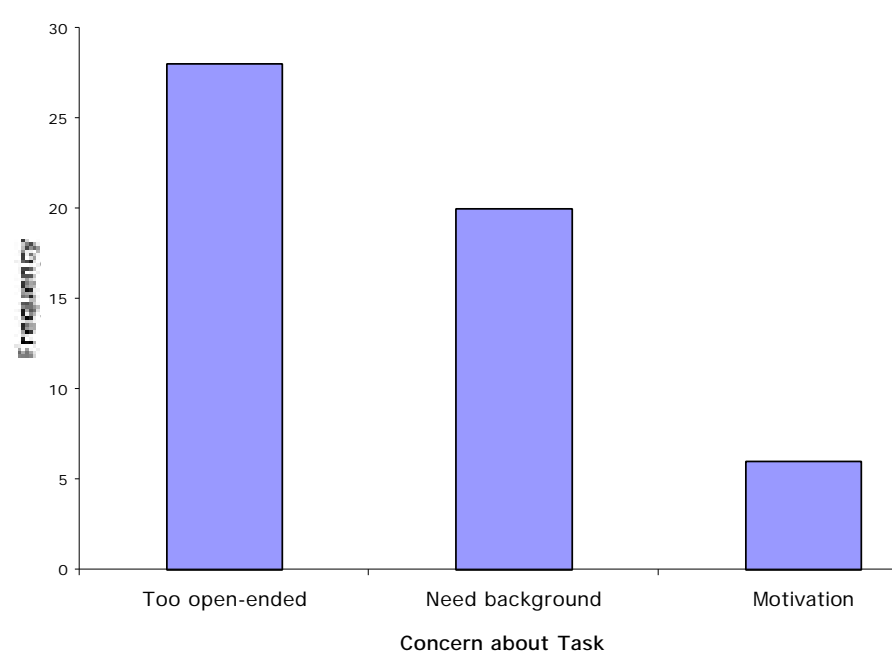

Figure 2. Teachers' concerns about their students encounters with the academic task. 
As suggested by the examples shown in Table 1 and the example dialogue we have just seen, most of the concerns about the task spring from the ambitious project-based nature of the task. Most issues raised reflected teachers' concerns about the open-ended nature of the task. They also considered whether their students would have the background conceptual knowledge and skills (e.g., data interpretation, oral presentation) required for the data intensive project. Finally, there was some attention to how to motivate students to engage in a long-term investigation about this particular dataset, but these concerns, raised early, faded after the first few meetings.

\section{Teachers' Designed Solutions}

We now turn to the solutions teachers developed to address the concerns they raised. The breakdown of comments concerning solutions that teachers proposed during the design meetings is shown in Figure 3.

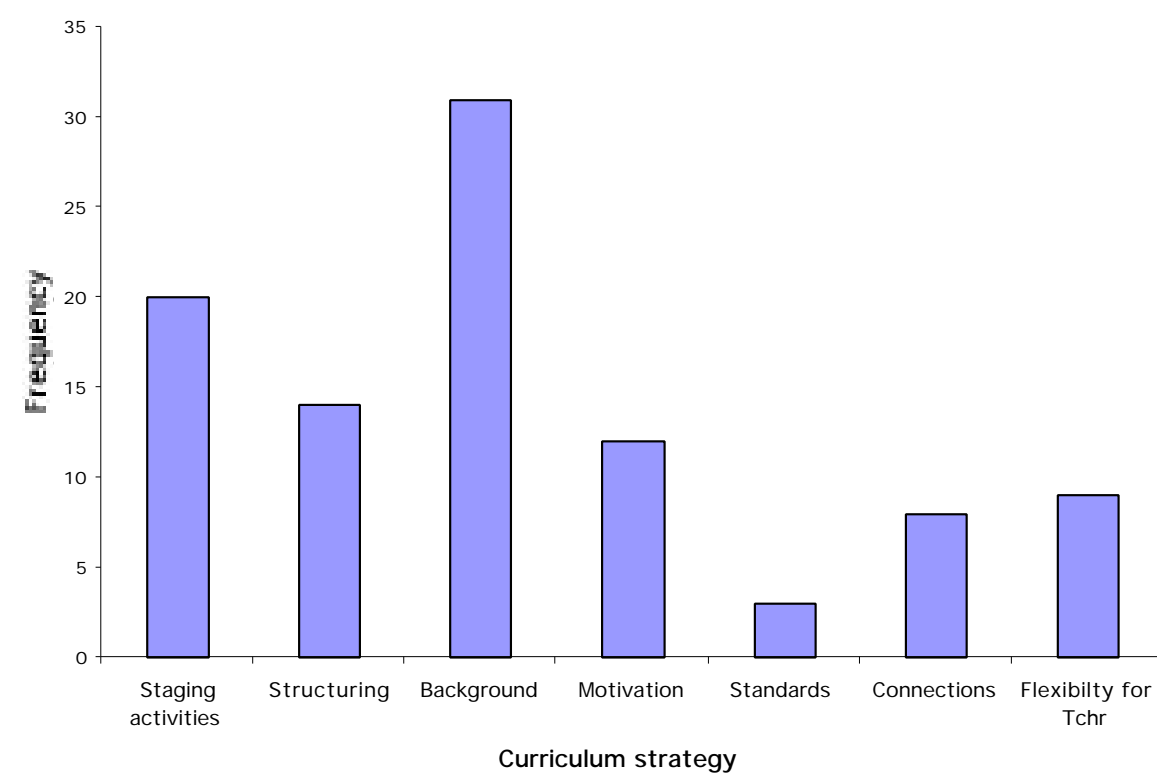

Figure 3. Teachers' proposed curricular solutions to issues raised by the group.

The three most frequent categories of solutions deal with helping students succeed in more open-ended and cognitively demanding learning tasks. Much of the group's attention was devoted to creating activities intended to help students develop the background knowledge (e.g., about interdependence of species) or skills (e.g., interpreting scatterplots) they would need in the investigation. The staging activities were created both to practice investigation skills in a more structured scale, and to reinforce the target background skills. Finally, much attention was given to structuring the task, by structuring expectations through rubrics and building journaling and peer critique into the task to help students focus on planing and reflection. In general, the proposals that were implemented preserved the student-directed nature of the core software investigation, but provided helpful structure to encourage students to plan and evaluate their investigations in an ongoing fashion. While the group entertained some simplifications of the task, such as directing students to particular subsets of the data, these solutions ultimately were abandoned in favor of strategies such as journaling and teacher feedback on students' investigation plans.

\section{The Tension Between Researcher and Teacher Approaches}

We now turn to the process that evolved in the group for dealing with the problems that were identified. To address this question, we consider the interaction styles and conversational patterns that emerged in the group from the different participants.

One important difference that emerges in reviewing the conversations that took place centers on a difference in focus or approach between the researchers and the teachers (see Table 2). The researchers were focused on developing a project-based curriculum that could be disseminated broadly. The researchers were driven by a particular interest in using this type of technology-supported curriculum to create opportunities for more meaningful science learning. Thus, the researchers tended to push a more analytical stance, and often attempted to 
get teachers to explain their ideas and articulate the rationale for the activities they proposed. The researchers wanted to discuss the goals, purposes, sequence, and rationale of every activity and idea brought to the table. The researchers wanted to produce a well-justified curriculum that implemented a driving question and integrated investigations. A related aspect is a focus on building a final product that could be distributed. This led the researchers to push for closure when alternatives were proposed. The need to create a product meant that activities and sequences had to be chosen and specified.

In contrast, the teachers, who had never before written a curriculum, tended not to focus on the endproduct, particularly in the first three months of the work circle. The teachers were more accustomed to informal "teacher talk" and sharing resources rather than deciding on specific activities and sequences which would be written into a final curriculum and enacted by other teachers. They were less focused on articulating and then resolving differences, seemingly less comfortable in critiquing each other, and tended to suggest that different approaches could be represented by choice within the curriculum. As Wilson, Miller, and Yerkes (1993) suggest, university discourse is argumentation and support, while being asked to "explain yourself" and "argue for what you believe" is typically not a central part of the culture of teaching (Wilson, et al., 1993, p. 116).

These views were echoed in interviews conducted with the teachers after the first phase of the work circle ended. In an interview after the work circle concluded, Ellen said, "They (The Northwestern researchers) were always talking and questioning, 'What do you think? How do you think this would work? Why don't you think this would.' (I felt like) get on with it, what do you want me to do, just tell me what you want me to do... I think sometimes it just seemed that they wanted to get into our brains, like what is your thought process on this whole thing. God, these people from Northwestern! Come on, we just want to teach a bunch of kids. What's the big deal? Come up with a lesson plan and go!" Jose expressed similar concerns when he stated, "We spent way too much time discussing it (lesson plan), sort of dissecting those ideas... The teachers there had different points. I had a different approach over how to introduce my students and how to lead them to the problem."

Table 2. Tensions in collaborative design of curriculum

\begin{tabular}{|l|l|}
\hline \multicolumn{1}{|c|}{ Researchers } & \multicolumn{1}{c|}{ Teachers } \\
\hline $\begin{array}{l}\text { Focused on building a final product so activities and } \\
\text { sequences had to be chosen and specified }\end{array}$ & $\begin{array}{l}\text { Accustomed to sharing resources without prescribing } \\
\text { activities for other classrooms and teachers }\end{array}$ \\
\hline Concerned with building scalable curriculum & $\begin{array}{l}\text { Prefer providing a menu of options and resources which } \\
\text { can be chosen and modified locally }\end{array}$ \\
\hline $\begin{array}{l}\text { Focus on articulating and debating rationale, making } \\
\text { hard choices based on fit with pedagogical model }\end{array}$ & $\begin{array}{l}\text { Focused on allowing for individual variation, tolerance } \\
\text { of different opinions }\end{array}$ \\
\hline
\end{tabular}

Despite these tensions, the team succeeded in creating a coherent curriculum, in which introductory activities are motivated within a driving question, and set the stage by building background knowledge and skill needed for the core investigation of the unit. Teachers generated most of the ideas for the activities in the unit, although often the push to tailor them to the project-based focus came from the researchers. For example, teachers felt that the graphs in The Galapagos Finches software were quite complex, and were concerned that students needed prior practice with graphs. The teachers' initial suggestions were various self-contained activities to teach the graphing skills needed. The faculty researcher suggested trying to tie the teaching of graphing more directly into the investigation itself. Eventually, through several meetings, the group converged on a design for a miniinvestigation, in which students are given a small dataset from the software database, and are instructed to study it to find patterns and then make a graph that backs up a claim they want to make about the data.

\section{Teacher Change?}

Did teachers change their beliefs and practices as a result of this process? Our analyses on this question must be more speculative. It is certainly the case that the two teachers who piloted the unit reported major changes in the learning experiences of the students during this unit. This was the students' first experience with such an extended project in which they worked with such a complex set of data for many class period, and where there was more than one simple right answer. So it seems reasonable to consider whether these teachers learned new teaching practices. However, we did not observe these teachers prior to the work circle experience, and so direct assessment of that issue is difficult. 
Another question to investigate is whether their beliefs seem to have shifted as a result of this experience. There is some evidence that the experience seems to have provoked a shift in some of the teachers in the group. The most dramatic shift in thinking is with Ellen, the teacher from Elmvale who piloted the unit. Here are three snapshots of Ellen's thinking about her students and the task:

- Kickoff Meeting 2/2/98: "My kids would have a heart attack if they saw this (activity)."

- Work Circle Meeting 3/1//98: "I think for my kids, they would get lost with all that information."

- Presentation at Summer Workshop 7/30/98: "I had concerns about the complexity. I didn't think my kids could do it. But I got a slap in the face. They showed me that they could do it."

Based on interviews, it appears this shift in Ellen's thinking occurred when she saw her students being successful with the computer investigation. Our conjecture is that the scaffolding in technology and curriculum helped make what appeared originally to be a very challenging task to one that was still difficult but nevertheless within the grasp of her students. The scaffolding helped make explicit the new task demands for explanation and evidence and helped students succeed in a complex investigation. The depth of student engagement and success led teachers to believe that project-based and technology-infused inquiry could work in their classrooms.

\section{Conclusions}

Our account underscores that teachers can indeed be actively involved in the design of curricular interventions, in this case the design of a technology-infused, project-based, middle school science curriculum. While teachers had initial concerns, some of them serious, they engaged in a concerted effort to create a curriculum to address concerns. Their involvement in the design process led to their deep engagement with both the science content and the pedagogical issues in the software investigation. This is the type of deep engagement with subject matter and pedagogy that can serve as a vehicle for teacher learning and change (Borko \& Putnam, 1996). The interplay of technology and pedagogy is particularly interesting. While technology was clearly the draw that brought teachers to the work circle, their concerns and much of the design process were occupied with issues of pedagogy. Technology was the hook that drew teachers into discussions of new pedagogy and content for their students.

\section{Acknowledgements}

This research was funded by the James S. McDonnell Foundation, Cognitive Studies for Educational Practice, and by the National Science Foundation Grant \#REC-9720383 to the Center for Learning Technologies in Urban Schools. For additional information about BGuILE software or curricula: http://www.ls.sesp.nwu.edu/bguile/

\section{References}

Blumenfeld, P. C., Soloway, E., Marx, R. W., Krajcik, J. S., Guzdial, M., \& Palincsar, A. (1991). Motivating project-based learning: Sustaining the doing, supporting the learning. Educational Psychologist, 26, 369398.

Borko, H., \& Putnam, R. T. (1996). Learning to teach. In D. C. Berliner \& R. C. Calfee (Eds.), Handbook of educational psychology (pp. 673-725). New York: McMillan.

Firestone, W. A. (1989). Educational policy as an ecology of games. Educational Researcher, 18(7), 18-24.

Fullan, M. (1991). The new meaning of educational change. New York: Teacher's College Press.

McLaughlin, M. W. (1987). Learning from experience: Lessons from policy implementation. Educational Evaluation and Policy Analysis, 9, 171-178.

PCAST (1997). Report to the President on the Use of Technology to Strengthen K-12 Education in the United States No. President's Committee of Advisors on Science and Technology: Panel on Educational Technology.

Spillane, J. P. (1999). State and local government relations in the era of standards based reform: Standards, state policy instruments, and local instructional policy-making. Educational Policy, 13.

Tabak, I., Smith, B. K., Sandoval, W. A., \& Reiser, B. J. (1996). Combining general and domain-specific strategic support for biological inquiry. In C. Frasson, G. Gauthier, \& A. Lesgold (Eds.), Intelligent Tutoring Systems: Third International Conference, ITS '96, (pp. 288-296). Montreal, Canada: Springer-Verlag.

Walker, L. J., \& Gomez, L. M. (1998). Two conceptions of project-based science: Projects through the lens of the science fair. In A. S. Bruckman, M. Guzdial, J. L. Kolodner, \& A. Ram (Eds.), International Conference of the Learning Sciences, (pp. 277-283). Atlanta, GA: AACE.

Wilson, S. M., Miller, C., \& Yerkes, C. (1993). Deeply rooted change: A tale of learning to teach adventurously. In D. K. Cohen, M. W. McLaughlin, \& J. E. Talbert (Eds.), Teaching for understanding: Challenges for policy and practice (pp. 84-129). San Francisco: Jossey-Bass. 